\title{
Associations between serum levels of insulin-like growth factor-I and bone mineral acquisition in pubertal children: a 3-year follow-up study in Hamamatsu, Japan
}

\author{
Katsuyasu Kouda ${ }^{1 *}$ (D) Masayuki ki $^{2}$, Kumiko Ohara ${ }^{2}$, Harunobu Nakamura ${ }^{3}$, Yuki Fujita ${ }^{2}$ and Toshimasa Nishiyama ${ }^{1}$
}

\begin{abstract}
Background: Epidemiological data regarding the association between serum levels of IGF-I and bone mineral acquisition during childhood are scarce. Here, we investigated the association between serum levels of IGF-I and bone status during puberty.

Methods: We analyzed prospective 3-year follow-up data of 254 community-dwelling children who completed both baselines (at age 11.2 years) and follow-up (at age 14.2 years) surveys in Hamamatsu, Japan. Total body (TB) bone area and bone mineral parameters were assessed using dual-energy X-ray absorptiometry.

Results: During the 3-year follow-up period, there were significant $(P<0.05)$ increases in total body less head (TBLH) areal bone mineral density (aBMD), TBLH bone mineral content (BMC), and TB bone area, and a significant decrease in TB bone mineral apparent density (BMAD, volumetric bone mineral density, VBMD). IGF-I levels showed significant positive relationships with TBLH BMC and TBLH aBMD at both baseline and follow-up. TBLH aBMD in boys and TB BMAD in girls at follow-up showed significant increases from the lowest to highest quartiles of baseline IGF-I levels after adjusting for confounding factors. Similarly, changes in TBLH aBMD in boys and TB BMAD in girls during the 3year follow-up period showed significant increases from the lowest to highest quartiles of baseline IGF-I levels after adjusting for confounding factors.
\end{abstract}

Conclusions: These results suggest that pubertal children with high levels of serum IGF-I tended to have high bone mineral acquisition later on.

Keywords: Bone development, Densitometry, General population, Somatomedins

\section{Background}

Skeletal mass and density at multiple sites, including the whole body, accumulate for the most part relatively early in life [1]. Bone mass content increases mainly during the first 3 years of life and during the pubertal growth spurt [2]. A longitudinal study reported that adolescence is clearly a critical time for bone mineralization because $26 \%$ of adult calcium is accumulated in the 2 years of

\footnotetext{
* Correspondence: koudakat@hirakata.kmu.ac.jp

${ }^{1}$ Department of Hygiene and Public Health, Kansai Medical University, 2-5-1

Shin-machi, Hirakata Osaka 573-1010," Japan

Full list of author information is available at the end of the article
}

peak skeletal growth [3]. Bone status during childhood, when peak bone mass is accumulated, is indicative of bone status in adulthood [4].

Circulating insulin-like growth factor-I (IGF-I) is a mediator of growth hormone and appears to have a direct impact on bone growth. The liver is the major source of IGF-I, where approximately $75 \%$ of circulating IGF-I originates [5]. In addition to circulating IGF-I, most tissues express IGF-I locally [5]. Bone growth relies not only on circulating IGF-I in blood [6], but also autocrine/paracrine IGF-I in tissues [7]. Direct evidence for the importance of the autocrine/paracrine role of IGF-I

(c) The Author(s). 2019 Open Access This article is distributed under the terms of the Creative Commons Attribution 4.0 International License (http://creativecommons.org/licenses/by/4.0/), which permits unrestricted use, distribution, and 
in body growth has been reported in animal models [7]. According to some experimental animal studies, hepatic IGF-I in the blood is not required for postnatal body growth $[7,8]$ and liver-derived circulating IGF-I exerts only a small effect on bone growth in mice [9]. In contrast, one experimental animal study reported that a threshold level of circulating IGF-I is necessary for normal bone growth [10]. Further characterization of the role of circulating IGF-I in bone acquisition in an epidemiological human study may have important implications for our understanding of skeletal growth during childhood [10].

However, information from epidemiological studies regarding the association between serum levels of IGF-I and bone mineral acquisition during childhood is scarce. To date, only two prospective studies have investigated the effect of IGF-I on bone mineral accrual in healthy children. The first, a longitudinal study targeting healthy 12 -year-old girls $(n=37)$, found no association between serum levels of IGF-I and gain in bone mass during an 18-month follow-up period [11]. The second, a prospective study targeting communitydwelling females (4- to 8-years-old at baseline, $n=76$ ), found a significant relationship between changes in IGF-I and changes in bone mineral parameters [12]. In the present 3-year follow-up study, which had a relatively large sample size $(n=254)$, we investigated associations between serum levels of IGF-I at age 11 years and bone mineral parameters such as bone area $\left(\mathrm{cm}^{2}\right)$, bone mineral content (BMC, g), areal bone mineral density $\left(\mathrm{aBMD}, \mathrm{g} / \mathrm{cm}^{2}\right)$, and volumetric bone mineral density (vBMD, $\mathrm{g} / \mathrm{cm}^{3}$ ) from age 11 to 14 years.

\section{Methods}

\section{Subjects}

The source population from which our subjects were selected consisted of all fifth-grade children registered in Aritama Elementary School and Sekishi Elementary School in Hamamatsu, Japan. There were 521 children (268 boys and 253 girls) in the two schools in November/December of 2010 and 2011 when the baseline survey was conducted, as previously described [13]. Since there were no other elementary schools in the school district, most children aged 11 years were enrolled in the two schools. Moreover, most children in this area went on to Sekishi Junior High School, the only junior high school in the area. After 36 months, a follow-up survey was conducted at this junior high school in December 2013 and 2014. Of the source population, we obtained complete baseline data for 408 children (202 boys and 206 girls) and complete follow-up data for 254 children (121 boys and 133 girls).

Prior to each survey, all parents and guardians received printed information regarding the study, including the dose of radiation exposure from dualenergy X-ray absorptiometry (DXA) and signed a letter of consent. Children were allowed to decline participation on their own accord at any time. This study was performed in accordance with the ethical standards set forth in the Declaration of Helsinki and approved by the Ethics Committee of the Kindai University Faculty of Medicine.

\section{Bone area and mineral measurements}

Measurements of whole-body bone area and bone mineral parameters were made using one DXA scanner (QDR-4500A, Hologic Inc, Bedford, MA, USA) mounted on a mobile examination car at each school. One experienced radiological technologist performed all scans and analyses at both baseline and follow-up surveys. The Step Phantom was used for quality control of the DXA scanner throughout the surveys. Subjects wore light clothing without metal or solid objects during the scanning process. Total body less head (TBLH) bone mineral content (BMC) and TBLH aBMD were measured in accordance with recommendations in the revised 2013 International Society for Clinical Densitometry Pediatric Official Positions [14]. The head region was separated by the neckline in the anterior scan image using standard manufacturer-recommended procedures [15]. Areal BMD (aBMD, $\left.\mathrm{g} / \mathrm{cm}^{2}\right)$ was calculated by dividing BMC (g) by the projected area of bone $\left(\mathrm{cm}^{2}\right)$. In addition, we calculated the bone mineral apparent density (BMAD), which accurately reflects changes in volumetric bone density during growth as an estimate of vBMD for children and adolescents, using the following formula: total body (TB) BMAD = TB BMC/(TB area ${ }^{2} /$ body height) [16].

Abbreviations for bone parameters can be summarized as follows: TBLH BMC, total body less head bone mineral content (g); TBLH aBMD, total body less head areal bone mineral density $\left(\mathrm{g} / \mathrm{cm}^{2}\right)$; TB BMAD, total body apparent bone mineral density as an estimate of volumetric bone density (vBMD).

\section{Other variables}

Bodyweight and height were measured in light clothing with no shoes. Height and weight were measured to the nearest $0.1 \mathrm{~cm}$ and $0.1 \mathrm{~kg}$, respectively. Body mass index $\left(\mathrm{kg} / \mathrm{m}^{2}\right)$ was calculated by dividing body weight by height squared. Blood samples were obtained by vein puncture at the time of the baseline survey, allowed to clot, and centrifuged. All serum samples were stored at $-80{ }^{\circ} \mathrm{C}$ until analysis. Serum IGF-I levels were measured using a commercially available kit (Quantikine ELISA, Human IGF-I Immunoassay, R\&D Systems, Inc., Minneapolis, MN, USA). The intra- and interassay coefficients of variation were $0.8 \%$ and $2.0 \%$, 
respectively. Serum 25-hydroxyvitamin D levels were measured using a radioimmunoassay (25-hydroxyvitamin D ${ }^{125}$ I RIA Kit; DiaSorin Inc., Stillwater, MN, USA), as previously described [17]. The intra- and inter-assay coefficients of variation were $5.2-9.5 \%$ and $6.3-10.8 \%$, respectively. We used a self-reported questionnaire comprising multiple-choice single-answer questions to obtain information regarding pubic hair appearance and time spent doing sedentary activities, such as watching television, playing video games, and using a mobile phone and/or personal computer. Together with their parents/guardians, children chose only one of the predefined options for pubic hair appearance (third grade, fourth grade, fifth grade, or no appearance) and sedentary behavior $(<1 \mathrm{~h} /$ day, $\geq 1$ and $<2 \mathrm{~h} /$ day, $\geq 2$ and $<3 \mathrm{~h} /$ day, $\geq 3$ and $<4 \mathrm{~h} /$ day, or $\geq 4$ $\mathrm{h} /$ day).

\section{Statistical analysis}

Differences between the study population and the dropout population were assessed using the unpaired $t$ test. The unpaired $t$ test or Mann-Whitney $U$ test was used to assess sex difference at the baseline survey. The paired $t$ test was used to assess differences between baseline and follow-up surveys. Pearson's correlation coefficient was used to evaluate relationships of IGF-I levels with anthropometric variables and bone parameters. In addition, subjects were stratified by sex-specific baseline IGF-I levels (from IGF-I Q1, the lowest quartile (Q) group of IGF-I levels, to IGF-I Q4, the highest quartile group of IGF-I levels) before assessing relationships between IGF-I levels and bone variables. ANOVA was performed to explore differences among quartile groups of IGF-I levels. ANCOVA was used to explore differences among quartile groups of IGF-I levels after adjusting for confounding factors such as 25 -hydroxyvitamin D, sedentary behavior, pubic hair appearance, weight, and height. To evaluate differences in bone mass at both baseline and follow-up among quartile groups, repeated measures ANOVA and repeated measures ANCOVA were performed. For trend tests on bone mineral parameters from the lowest to highest quartiles of IGF-I levels, multiple linear regression analysis was performed, with bone mineral parameters in each individual as the explanatory variable, and quartiles of IGF-I levels and confounding factors including 25-hydroxyvitamin D and others as dependent variables. $P<0.05$ was considered statistically significant. All analyses were performed using SPSS Statistics Desktop for Japan, Version 22 (IBM Japan, Ltd., Tokyo, Japan).

\section{Results}

Characteristics of the study population (follow-up subjects) and the dropout population are shown in Table 1.
At baseline, there were no significant differences in anthropometric and bone variables between the study population and the dropout population. Serum levels of IGF-I in girls were significantly higher than those in boys at baseline. In addition, pubic hair in girls appeared significantly earlier than in boys. From baseline to follow-up, there were significant increases in height, weight, TBLH BMC, TB bone area, and TBLH aBMD in both boys and girls. In contrast, TB BMAD significantly decreased from baseline to follow-up.

Table 2 shows linear relationships of serum levels of IGF-I with anthropometric variables and bone mineral parameters. IGF-I levels showed significant positive relationships with height, weight, TBLH BMC, and TBLH aBMD in both sexes and at both baseline and follow-up. On the other hand, there were significant inverse relationships between IGF-I levels and TB BMAD in both sexes at baseline.

Relationships between bone mineral parameters and quartile groups of IGF-I levels at baseline and follow-up are shown in Table 3. From the lowest to highest quartiles of baseline IGF-I levels, TBLH aBMD in boys showed a significant positive increase at follow-up after adjusting for confounding factors. In girls, TB BMAD at follow-up showed a significant positive increase from the lowest to highest quartiles of baseline IGF-I levels after adjusting for confounding factors.

Table 4 shows the relationships between changes in bone mineral parameters from baseline to follow-up and quartile groups of baseline IGF-I levels. In boys, there was a significant positive increase in changes in TBLH BMC from the lowest to highest quartiles of baseline IGF-I levels after adjusting for confounding factors, including height. Changes in TBLH aBMD also showed a significant positive increase after adjusting for confounding factors. In girls, there was a significant positive increase in changes in $\mathrm{TB}$ BMAD from the lowest to highest quartiles of baseline IGF-I levels after adjusting for confounding factors.

\section{Discussion}

Mechanical loading stimulates skeletal growth, and the response to mechanical loading is a complex process regulated by multiple signaling pathways including that of IGF-I [18]. However, little has been reported regarding the relationship between serum levels of IGF-I and bone status during childhood in prospective cohort studies. The present prospective 3year follow-up study of community-dwelling children showed that serum levels of IGF-I at baseline were related to the acquisition of $\mathrm{BMC}, \mathrm{aBMD}$, and estimated vBMD later on. Pubertal children who had high levels of baseline serum IGF-I tended to have 
Table 1 Characteristics of the study population and dropout population

\begin{tabular}{|c|c|c|c|c|c|c|c|c|c|c|c|}
\hline & \multicolumn{7}{|c|}{ Study population } & \multicolumn{4}{|c|}{ Dropout population } \\
\hline & \multicolumn{3}{|l|}{ Baseline } & \multicolumn{2}{|l|}{ Follow-up } & \multicolumn{2}{|c|}{$\begin{array}{l}\text { aBaseline vs } \\
\text { follow-up }\end{array}$} & \multicolumn{2}{|l|}{ Baseline } & \multicolumn{2}{|c|}{$\begin{array}{l}\text { bStudy vs } \\
\text { dropout } \\
\text { populations }\end{array}$} \\
\hline & $\begin{array}{l}\text { Boys, } \\
N=121\end{array}$ & $\begin{array}{l}\text { Girls, } \\
\mathrm{N}=133\end{array}$ & $\begin{array}{l}\text { bBoys vs } \\
\text { girls }\end{array}$ & $\begin{array}{l}\text { Boys, } \\
N=121\end{array}$ & Girls, $N=133$ & Boys & $\overline{\text { Girls }}$ & $\begin{array}{l}\text { Boys, } \\
N=81\end{array}$ & $\begin{array}{l}\text { Girls, } \\
N=73\end{array}$ & Boys & $\overline{\text { Girls }}$ \\
\hline Age (years) & $11.2 \pm 0.3$ & $11.2 \pm 0.3$ & ns & $14.2 \pm 0.3$ & $14.2 \pm 0.3$ & $\begin{array}{l}< \\
0.001\end{array}$ & $\begin{array}{l}< \\
0.001\end{array}$ & $11.2 \pm 0.3$ & $11.2 \pm 0.3$ & ns & $\mathrm{ns}$ \\
\hline Height (cm) & $141 \pm 6$ & $143 \pm 7$ & 0.007 & $162 \pm 6$ & $155 \pm 5$ & $\begin{array}{l}< \\
0.001\end{array}$ & $\begin{array}{l}< \\
0.001\end{array}$ & $142 \pm 6$ & $143 \pm 7$ & ns & ns \\
\hline Weight (kg) & $34.7 \pm 7.4$ & $35.1 \pm 5.9$ & ns & $49.9 \pm 8.4$ & $47.0 \pm 5.8$ & $\begin{array}{l}< \\
0.001\end{array}$ & $\begin{array}{l}< \\
0.001\end{array}$ & $35.4 \pm 7.1$ & $35.5 \pm 8.7$ & ns & ns \\
\hline TBLH BMC (g) & $644 \pm 140$ & $700 \pm 162$ & 0.003 & $1143 \pm 251$ & $1044 \pm 180$ & $\begin{array}{l}< \\
0.001\end{array}$ & $\begin{array}{l}< \\
0.001\end{array}$ & $656 \pm 121$ & $690 \pm 178$ & ns & ns \\
\hline TB bone area $\left(\mathrm{cm}^{2}\right)$ & $1288 \pm 174$ & $1336 \pm 186$ & 0.036 & $1789 \pm 211$ & $1680 \pm 153$ & $\begin{array}{l}< \\
0.001\end{array}$ & $\begin{array}{l}< \\
0.001\end{array}$ & $1305 \pm 155$ & $1329 \pm 195$ & ns & ns \\
\hline TBLH aBMD $\left(\mathrm{g} / \mathrm{cm}^{2}\right)$ & $0.609 \pm 0.040$ & $0.624 \pm 0.050$ & 0.005 & $0.739 \pm 0.074$ & $0.720 \pm 0.062$ & $\begin{array}{l}< \\
0.001\end{array}$ & $\begin{array}{l}< \\
0.001\end{array}$ & $0.613 \pm 0.037$ & $0.618 \pm 0.057$ & ns & ns \\
\hline TB BMAD $\left(\mathrm{g} / \mathrm{cm}^{3}\right)$ & $0.081 \pm 0.008$ & $0.080 \pm 0.006$ & ns & $0.075 \pm 0.004$ & $0.078 \pm 0.005$ & $\begin{array}{l}< \\
0.001\end{array}$ & 0.003 & $0.081 \pm 0.007$ & $0.080 \pm 0.007$ & ns & ns \\
\hline $\begin{array}{l}\text { 25-hydroxyvitamin } \\
\text { D (ng/mL) }\end{array}$ & $34.3 \pm 7.8$ & $29.6 \pm 7.7$ & $<0.001$ & & & & & & & & \\
\hline IGF-I (ng/mL) & $198 \pm 80$ & $281 \pm 81$ & $<0.001$ & & & & & & & & \\
\hline \multicolumn{12}{|l|}{$\begin{array}{l}\text { Sedentary behavior } \\
\text { (media use), } N(\%)\end{array}$} \\
\hline$<1$ h/day & $29(24)$ & $33(25)$ & ns & & & & & & & & \\
\hline$\geq 1,<2$ h/day & $54(45)$ & $63(47)$ & & & & & & & & & \\
\hline$\geq 2,<3$ h/day & $20(17)$ & $29(22)$ & & & & & & & & & \\
\hline$\geq 3,<4$ h/day & $11(9)$ & $6(5)$ & & & & & & & & & \\
\hline$\geq 4$ h/day & $7(6)$ & $2(2)$ & & & & & & & & & \\
\hline \multicolumn{12}{|l|}{$\begin{array}{l}\text { Pubic hair } \\
\text { appearance, } N(\%)\end{array}$} \\
\hline$<$ Grade 5 & $0(0)$ & $10(8)$ & $<0.001$ & & & & & & & & \\
\hline Grade 5 & $8(7)$ & $36(27)$ & & & & & & & & & \\
\hline No appearance & $113(93)$ & $87(65)$ & & & & & & & & & \\
\hline
\end{tabular}

$N$ number, $n s$ not significant, $T B L H$ total body less head, $B M C$ bone mineral content, $T B$ total body, $a B M D$ areal bone mineral density,

$B M A D$ bone mineral apparent density as an estimate of volumetric bone mineral density, IGF-I insulin-like growth factor-I

Values represent mean \pm SD or $N(\%)$

${ }^{\text {aPaired }} t$ test was used to assess the difference between baseline and follow-up surveys

${ }^{\mathrm{b}} P$ value calculated with unpaired $t$ test or Mann-Whitney $U$ test. $P<0.05$ was considered statistically significant

high bone mass at follow-up. Mean serum IGF-I levels reportedly increase slowly in prepubertal children and increase steeply during puberty, and peak serum levels of IGF-I are observed in girls aged 14.5 years and in boys aged 15.5 years [19, 20]. According to previous reports, the mean age of peak calcium accretion is 14.0 years for boys and 12.5 years for girls [3]. In the present study, subjects were followed over the course of 3 years from 11 to 14 years of age, and our study population was near the age at which calcium accretion and levels of serum IGF-I are maximal. A prospective study that spanned up to 9 years by Breen et al. reported a significant positive relationship between changes in IGF-I levels and changes in BMC among 78 children aged 4-8 years at baseline [12]. On the other hand, a study with a relatively small sample size $(n=37)$ reported no significant association between IGF-I levels and gain in bone mass among children [11]. Along with these previous reports, our present findings suggest that serum levels of IGF-I in children undergoing skeletal growth spurt are associated with future bone mass acquisition.

In the baseline survey, IGF-I levels showed significant positive relationships with bone area, $\mathrm{BMC}$, and 
Table 2 Correlation coefficients between IGF-I levels at baseline and other variables

\begin{tabular}{|c|c|c|c|c|}
\hline & \multicolumn{2}{|c|}{ Boys, $N=121$} & \multicolumn{2}{|c|}{ Girls, $N=133$} \\
\hline & $r$ & $P$ & $r$ & $P$ \\
\hline \multicolumn{5}{|l|}{ Baseline } \\
\hline Height & 0.510 & $<0.001$ & 0.606 & $<0.001$ \\
\hline Weight & 0.473 & $<0.001$ & 0.613 & $<0.001$ \\
\hline TBLH BMC & 0.521 & $<0.001$ & 0.600 & $<0.001$ \\
\hline TB bone area & 0.557 & $<0.001$ & 0.637 & $<0.001$ \\
\hline TBLH aBMD & 0.371 & $<0.001$ & 0.512 & $<0.001$ \\
\hline TB BMAD & -0.435 & $<0.001$ & -0.457 & $<0.001$ \\
\hline \multicolumn{5}{|l|}{ Follow-up } \\
\hline Height & 0.420 & $<0.001$ & 0.275 & $<0.001$ \\
\hline Weight & 0.489 & $<0.001$ & 0.434 & $<0.001$ \\
\hline TBLH BMC & 0.543 & $<0.001$ & 0.493 & $<0.001$ \\
\hline TB bone area & 0.554 & $<0.001$ & 0.450 & $<0.001$ \\
\hline TBLH aBMD & 0.455 & $<0.001$ & 0.461 & $<0.001$ \\
\hline TB BMAD & -0.129 & ns & 0.140 & ns \\
\hline
\end{tabular}

IGF-I insulin-like growth factor-I, $N$ number, $T B L H$ total body less head, $B M C$, bone mineral content, $T B$ total body, $a B M D$ areal bone mineral density, $B M A D$ bone mineral apparent density as an estimate of volumetric bone mineral density, ns not significant

Pearson's correlation coefficient was used. $P<0.05$ was considered statistically significant

aBMD in both sexes, and a significant inverse relationship with vBMD in both sexes. In addition, aBMD significantly increased from 11 to 14 years of age, while vBMD significantly decreased during the same period. aBMD $\left(\mathrm{g} / \mathrm{cm}^{2}\right)$ is calculated by dividing BMC (g) by the projected area of bone $\left(\mathrm{cm}^{2}\right)$. On the other hand, vBMD is calculated using bone area and bone depth. Bone size and mineral content reportedly increase independently during puberty, with the increase in bone size being proportionally faster than the rate of mineralization, and vBMD falls as bone size increases during early puberty [21]. Other studies have reported that accrual of bone mass mainly results from an increase in bone size, with minor changes in vBMD during growth [22], and that $v B M D$ remains almost constant during pubertal development, in contrast to the increase in aBMD during puberty $[23,24]$. The normative reference for Thai children has reported that vBMD of the lumbar spine decreases from age 8-9 years to age 10-11 years in boys and from age 10-11 years to age 1112 years in girls, while aBMD of the lumbar spine increases during the same periods in both sexes [25]. Consistent with this, we found significant decreases in vBMD from baseline to follow-up, and a significant increase in aBMD. We also found sex differences in the relationship between IGF-I levels and bone parameters, with a more prominent decrease in vBMD in boys than in girls. Furthermore, baseline IGF-I levels were related with BMC and aBMD at follow-up in boys and vBMD at follow-up in girls. In general, differences in biological age have been observed between boys and girls. At ages 11 and 14 years, boys are on average 1.5 to 2 years delayed in physical maturity. Consistent with this, the present study observed a significant difference in pubic hair appearance between boys and girls at age 11 years. In addition, maximal increase in bone variables occurs earlier in girls than in boys [21], and sex differences in bone microarchitecture, geometry, density, and strength from childhood to early adulthood have also been reported [26]. Differences in bone growth between boys and girls may account for the sex differences in the relationship between IGF-I levels and bone mineral parameters.

The present study has several strengths. First, this is the first population-based prospective cohort study on this topic, which found a significant positive relationship between baseline levels of serum IGF-I and bone mineral acquisition later on. Second, the present study reflects the health status of community-dwelling children in Japan. The temporal sequence of exposure (IGF-I levels at baseline) and outcome (bone parameters at follow-up) in the cohort design strengthens the process of inferring cause-effect relationships. Third, the study population was relatively large compared with those of similar studies on this topic [11, 12]. Fourth, the present study is a single-center cohort and thus is free from inter-center variation. Fifth, a single radiological technologist performed all scans and scan analyses using a single DXA scanner.

There are also several limitations worth noting. First, the study population consisted only of $62.3 \%$ of participants from the baseline survey. Participant dropout may have resulted in self-selection bias. However, there were no significant differences in anthropometric and bone variables between the study population and the dropout population, which limited the impact of self-selection bias. Second, we did not obtain information regarding the tanner scale, physical activity, or nutrient intake, which could be associated with IGF-I levels and bone mineral parameters.

In conclusion, the present population-based prospective cohort study found that serum levels of IGFI at 11 years of age were associated with the acquisition of BMC, aBMD, and vBMD later on. These findings suggest that children with high levels of serum IGF-I tend to have high bone mass during pubertal development. 
Table 3 Relationships between bone mineral parameters and quartile groups of IGF-I levels

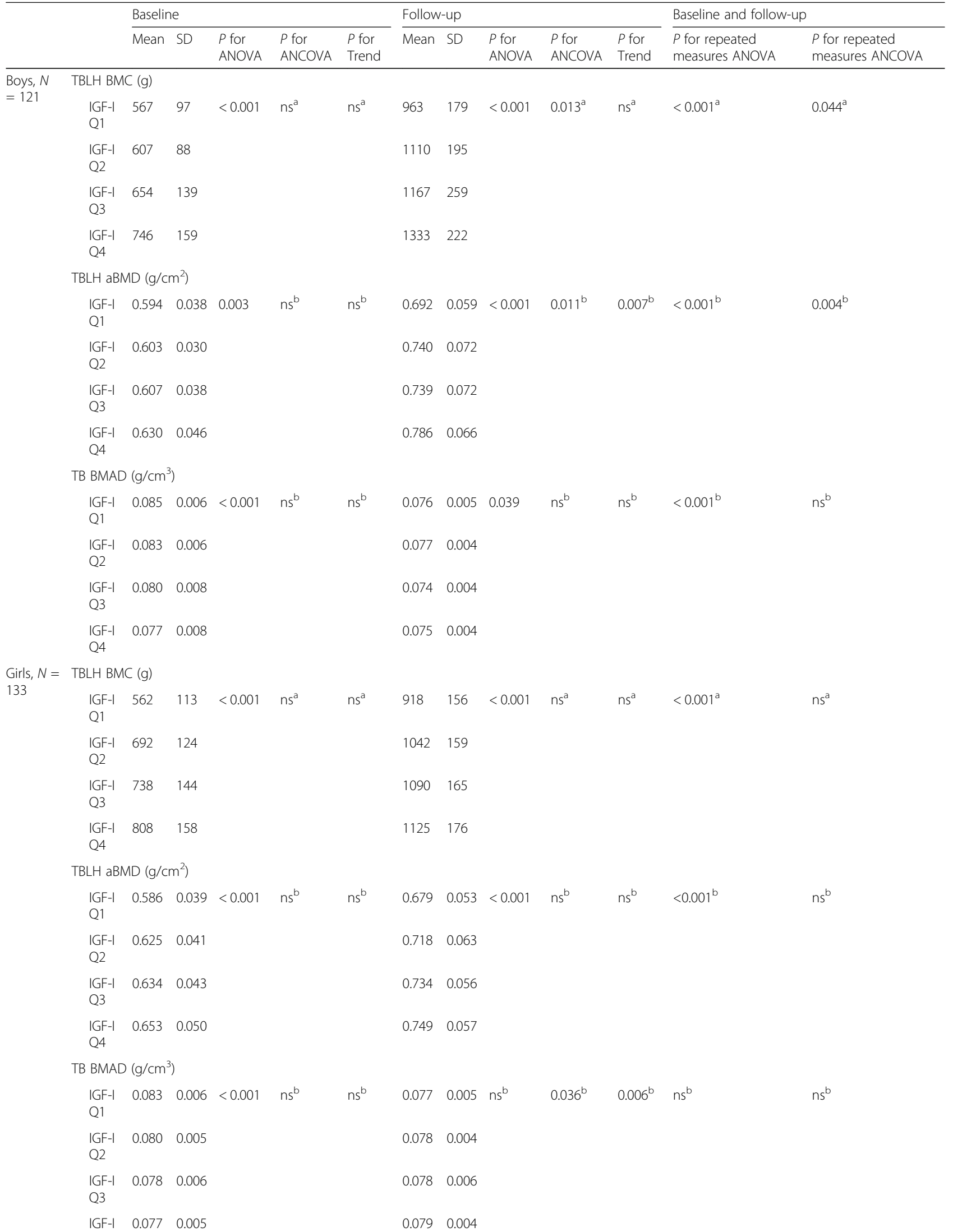


Table 3 Relationships between bone mineral parameters and quartile groups of IGF-I levels (Continued)

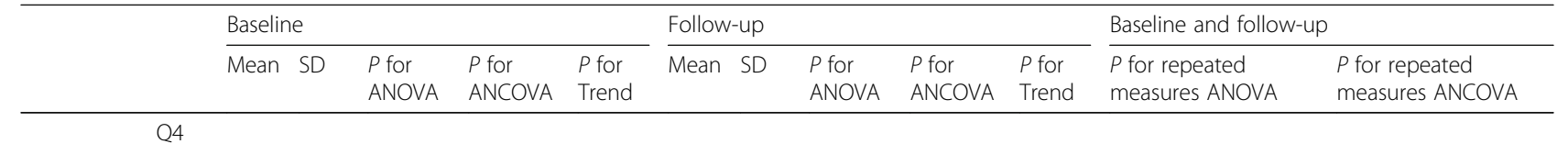

IGF-I insulin-like growth factor-l; TBLH total body less head, $B M C$ bone mineral content, $N$ number, $Q$ quartile, $n s$ not significant, $a B M D$ areal bone mineral density, TB total body, BMAD bone mineral apparent density as an estimate of volumetric bone mineral density, IGF-I Q1 the lowest quartile group of IGF-I levels, IGF-I Q4 the highest quartile group of IGF-I levels

ANOVA and ANCOVA were performed to explore differences among quartiles

Multiple linear regression analysis was performed for trend tests from lowest to highest quartiles of IGF-I levels

Repeated measures ANOVA and ANCOVA were performed to explore differences among quartiles. $P<0.05$ was considered statistically significant

${ }^{a}$ Adjusted for 25-hydroxyvitamin D, sedentary behavior, pubic hair appearance, weight, and height at baseline

${ }^{\mathrm{b}}$ Adjusted for 25-hydroxyvitamin $\mathrm{D}$, sedentary behavior, pubic hair appearance, and weight at baseline

Table 4 Relationships between change in bone mineral parameters from baseline to follow-up and quartile groups of IGF-I levels

\begin{tabular}{|c|c|c|c|c|c|c|}
\hline & & Mean & SD & $P$ for ANOVA & $P$ for ANCOVA & $P$ for trend \\
\hline \multirow[t]{15}{*}{ Boys, $N=121$} & Change in TBLH BMC (g) & & & & & \\
\hline & IGF-I Q1 & 396 & 112 & $<0.001$ & $0.005^{\mathrm{a}}$ & $0.002^{\mathrm{a}}$ \\
\hline & |GF-| Q2 & 502 & 144 & & & \\
\hline & IGF-I Q3 & 514 & 158 & & & \\
\hline & IGF-I Q4 & 586 & 114 & & & \\
\hline & Change in TBLH aBMD ( & & & & & \\
\hline & IGF-I Q1 & 0.098 & 0.041 & $<0.001$ & $0.010^{b}$ & $0.012^{b}$ \\
\hline & IGF-I Q2 & 0.138 & 0.062 & & & \\
\hline & IGF-I Q3 & 0.132 & 0.056 & & & \\
\hline & IGF-I Q4 & 0.155 & 0.048 & & & \\
\hline & Change in TB BMAD ( $\mathrm{g} / \mathrm{C}$ & & & & & \\
\hline & |GF-| Q1 & -0.009 & 0.005 & $<0.001$ & $n s^{b}$ & $n s^{\mathrm{b}}$ \\
\hline & IGF-I Q2 & -0.006 & 0.006 & & & \\
\hline & IGF-I Q3 & -0.006 & 0.007 & & & \\
\hline & IGF-I Q4 & -0.002 & 0.007 & & & \\
\hline \multirow[t]{15}{*}{ Girls, $N=133$} & Change in TBLH BMC (g) & & & & & \\
\hline & IGF-I Q1 & 356 & 90 & ns & $\mathrm{ns}^{\mathrm{a}}$ & $\mathrm{ns}^{\mathrm{a}}$ \\
\hline & IGF-I Q2 & 350 & 99 & & & \\
\hline & IGF-I Q3 & 352 & 106 & & & \\
\hline & IGF-I Q4 & 317 & 108 & & & \\
\hline & Change in TBLH aBMD ( & & & & & \\
\hline & IGF-I Q1 & 0.093 & 0.043 & ns & $n s^{b}$ & $n s^{b}$ \\
\hline & IGF-I Q2 & 0.093 & 0.049 & & & \\
\hline & IGF-I Q3 & 0.100 & 0.053 & & & \\
\hline & IGF-I Q4 & 0.096 & 0.046 & & & \\
\hline & Change in TB BMAD ( $\mathrm{g} / \mathrm{C}$ & & & & & \\
\hline & IGF-I Q1 & -0.007 & 0.006 & $<0.001$ & $n s^{b}$ & $0.017^{b}$ \\
\hline & IGF-I Q2 & -0.002 & 0.006 & & & \\
\hline & IGF-I Q3 & 0.000 & 0.006 & & & \\
\hline & IGF-| Q4 & 0.002 & 0.005 & & & \\
\hline
\end{tabular}

IGF-I insulin-like growth factor-I, TBLH total body less head, $B M C$ bone mineral content, $N$ number, $Q$ quartile, $a B M D$ areal bone mineral density, TB total body, $B M A D$ bone mineral apparent density as an estimate of volumetric bone mineral density, ns not significant, IGF-I Q1 the lowest quartile group of IGF-I levels, IGF-I Q4 the highest quartile group of IGF-I levels

ANOVA and ANCOVA were performed to explore differences among quartiles

Multiple linear regression analysis was performed for trend tests from the lowest to highest quartile of IGF-I

$P<0.05$ was considered statistically significant

${ }^{a}$ Adjusted for 25-hydroxyvitamin $\mathrm{D}$, sedentary behavior, pubic hair appearance, weight, and height at baseline

${ }^{\mathrm{b}}$ Adjusted for 25 -hydroxyvitamin $\mathrm{D}$, sedentary behavior, pubic hair appearance, and weight at baseline 


\section{Abbreviations}

aBMD: Areal bone mineral density; BMAD: Bone mineral apparent density; BMC: Bone mineral content; DXA: Dual-energy X-ray absorptiometry; IGFI: Insulin-like growth factor-l; Q: Quartile; TB: Total body; TBLH: Total body less head; vBMD: Volumetric bone mineral density

\section{Acknowledgements}

The authors thank the teaching staff of Aritama Elementary School, Sekishi Elementary School, and Sekishi Junior High School, and Dr. Toshiko Okamoto for their support.

\section{Authors' contributions}

$\mathrm{KK}$ and $\mathrm{YF}$ contributed to the study conception and design. $\mathrm{KK}, \mathrm{MI}, \mathrm{KO}, \mathrm{HN}$ YF, and TN helped in data acquisition, analysis, or interpretation. KK, MI, KO $H N, Y F$, and TN contributed to the drafting of the manuscript or revising it critically for important intellectual content. KK takes responsibility for the integrity of the data analysis. KK, MI, KO, HN, YF, and TN approved the final version of the manuscript.

\section{Funding}

This work was supported by Grants-in-Aid for Scientific Research (KAKENHI Grant Numbers 21657068, 22370092, 24370101, and 26291100) from the Japan Society for the Promotion of Science. The funding bodies had no role in designing the study, collecting, analyzing, and interpreting the data, writing the manuscript, or deciding where to submit the manuscript for publication.

\section{Availability of data and materials}

Not applicable.

\section{Ethics approval and consent to participate}

This study was performed in accordance with the ethical standards set forth in the Declaration of Helsinki and approved by the Ethics Committee of the Kindai University Faculty of Medicine. All parents and guardians received printed information regarding the study and signed a letter of consent.

\section{Consent for publication}

Not applicable.

\section{Competing interests}

The authors declare that they have no competing interests.

\section{Author details}

'Department of Hygiene and Public Health, Kansai Medical University, 2-5-1 Shin-machi, Hirakata Osaka 573-1010," Japan. 'Department of Public Health, Kindai University Faculty of Medicine, 377-2 Oono-Higashi, Osaka-Sayama Osaka 589-8511, Japan. ${ }^{3}$ Department of Health Promotion and Education, Graduate School of Human Development and Environment, Kobe University, 3-11 Tsurukabuto, Nada, Kobe Hyogo 657-8501 "Japan.

\section{Received: 6 February 2019 Accepted: 19 November 2019}

Published online: 05 December 2019

\section{References}

1. Matkovic V, Jelic T, Wardlaw GM, llich JZ, Goel PK, Wright JK, Andon $M B$, Smith KT, Heaney RP. Timing of peak bone mass in Caucasian females and its implication for the prevention of osteoporosis. Inference from a cross-sectional model. J Clin Invest. 1994;93:799-808.

2. Perez-Lopez FR, Chedraui P, Cuadros-Lopez JL. Bone mass gain during puberty and adolescence: deconstructing gender characteristics. Curr Med Chem. 2010;17:453-66.

3. Bailey DA, Martin AD, McKay HA, Whiting S, Mirwald R. Calcium accretion in girls and boys during puberty: a longitudinal analysis. J Bone Miner Res. 2000;15:2245-50.

4. Weaver CM, Gordon CM, Janz KF, Kalkwarf HJ, Lappe JM, Lewis R, O'Karma M, Wallace TC, Zemel BS. The National Osteoporosis Foundation's position statement on peak bone mass development and lifestyle factors: a systematic review and implementation recommendations. Osteoporos Int. 2016;27:1281-386.
5. Bikle DD, Tahimic C, Chang W, Wang Y, Philippou A, Barton ER. Role of IGF-I signaling in muscle bone interactions. Bone. 2015;80:79-88.

6. Veldhuis JD, Roemmich JN, Richmond EJ, Rogol AD, Lovejoy JC, SheffieldMoore M, Mauras N, Bowers CY. Endocrine control of body composition in infancy, childhood, and puberty. Endocr Rev.

2005;26:114-46.

7. Yakar S, Liu JL, Stannard B, Butler A, Accili D, Sauer B, LeRoith D. Normal growth and development in the absence of hepatic insulin-like growth factor I. Proc Natl Acad Sci U S A. 1999:96:7324-9.

8. Sjogren K, Liu JL, Blad K, Skrtic S, Vidal O, Wallenius V, LeRoith D, Tornell J, Isaksson OG, Jansson JO, Ohlsson C. Liver-derived insulin-like growth factor I (IGF-I) is the principal source of IGF-I in blood but is not required for postnatal body growth in mice. Proc Natl Acad Sci U S A. 1999;96:7088-92.

9. Sjogren K, Sheng M, Moverare S, Liu JL, Wallenius K, Tornell J, Isaksson O, Jansson JO, Mohan S, Ohlsson C. Effects of liver-derived insulin-like growth factor I on bone metabolism in mice. J Bone Miner Res. 2002;17:1977-87.

10. Yakar S, Rosen CJ, Beamer WG, Ackert-Bicknell CL, Wu Y, Liu JL, Ooi GT, Setser J, Frystyk J, Boisclair YR, LeRoith D. Circulating levels of IGF-1 directly regulate bone growth and density. J Clin Invest. 2002:110:771-81.

11. Cadogan J, Blumsohn A, Barker ME, Eastell R. A longitudinal study of bone gain in pubertal girls: anthropometric and biochemical correlates. J Bone Miner Res. 1998;13:1602-12.

12. Breen ME, Laing EM, Hall DB, Hausman DB, Taylor RG, Isales CM, Ding KH, Pollock NK, Hamrick MW, Baile CA, Lewis RD. 25-hydroxyvitamin D insulin-like growth factor-l, and bone mineral accrual during growth. Clin Endocrinol Metab. 2011;96:E89-98.

13. Kouda K, Ohara K, Fujita Y, Nakamura H, Tachiki T, Iki M. Relationships between serum leptin levels and bone mineral parameters in schoolaged children: a 3-year follow-up study. J Bone Miner Metab. 2019;37:152-60

14. Crabtree NJ, Arabi A, Bachrach LK, Fewtrell M, El-Hajj Fuleihan G, Kecskemethy HH, Jaworski M, Gordon CM, International Society for Clinical D. Dual-energy X-ray absorptiometry interpretation and reporting in children and adolescents: the revised 2013 ISCD Pediatric Official Positions. J Clin Densitom. 2014;17:225-42.

15. Laskey MA. Dual-energy X-ray absorptiometry and body composition. Nutrition. 1996:12:45-51.

16. Katzman DK, Bachrach LK, Carter DR, Marcus R. Clinical and anthropometric correlates of bone mineral acquisition in healthy adolescent girls. J Clin Endocrinol Metab. 1991;73:1332-9.

17. Kouda K, Nakamura H, Fujita Y, Ohara K, Iki M. Vitamin D status and body fat measured by dual-energy $\mathrm{X}$-ray absorptiometry in a general population of Japanese children. Nutrition. 2013;29:1204-8.

18. Tian F, Wang Y, Bikle DD. IGF-1 signaling mediated cell-specific skeletal mechano-transduction. J Orthop Res. 2018;36:576-83.

19. Juul A, Bang P, Hertel NT, Main K, Dalgaard P, Jorgensen K, Muller J, Hall K, Skakkebaek NE. Serum insulin-like growth factor-I in 1030 healthy children, adolescents, and adults: relation to age, sex, stage of puberty, testicular size, and body mass index. J Clin Endocrinol Metab. 1994:78:744-52

20. Bereket A, Turan S, Omar A, Berber M, Ozen A, Akbenlioglu C, Haklar G. Serum IGF-I and IGFBP-3 levels of Turkish children during childhood and adolescence: establishment of reference ranges with emphasis on puberty. Horm Res. 2006;65:96-105.

21. Magarey AM, Boulton TJ, Chatterton BE, Schultz C, Nordin BE, Cockington RA. Bone growth from 11 to 17 years: relationship to growth, gender and changes with pubertal status including timing of menarche. Acta Paediatr. 1999:88:139-46.

22. Davies JH, Evans BA, Gregory JW. Bone mass acquisition in healthy children. Arch Dis Child. 2005:90:373-8.

23. Lu PW, Cowell CT, LLoyd-Jones SA, Briody JN, Howman-Giles R. Volumetric bone mineral density in normal subjects, aged 5-27 years. J Clin Endocrinol Metab. 1996:81:1586-90. 
24. Neu CM, Manz F, Rauch F, Merkel A, Schoenau E. Bone densities and bone size at the distal radius in healthy children and adolescents: a study using peripheral quantitative computed tomography. Bone. 2001;28:227-32.

25. Nakavachara P, Pooliam J, Weerakulwattana L, Kiattisakthavee $P$,

Chaichanwattanakul K, Manorompatarasarn R, Chokephaibulkit K, Viprakasit $\mathrm{V}$. A normal reference of bone mineral density (BMD) measured by dual energy X-ray absorptiometry in healthy thai children and adolescents aged 5-18 years: a new reference for Southeast Asian Populations. PLoS ONE. 2014;9:e97218

26. Gabel L, Macdonald HM, McKay HA. Sex differences and growth-related adaptations in bone microarchitecture, geometry, density, and strength from childhood to early adulthood: a mixed longitudinal HR-pQCT study. J Bone Miner Res. 2017;32:250-63.

\section{Publisher's Note}

Springer Nature remains neutral with regard to jurisdictional claims in published maps and institutional affiliations.

Ready to submit your research? Choose BMC and benefit from:

- fast, convenient online submission

- thorough peer review by experienced researchers in your field

- rapid publication on acceptance

- support for research data, including large and complex data types

- gold Open Access which fosters wider collaboration and increased citations

- maximum visibility for your research: over $100 \mathrm{M}$ website views per year

At $B M C$, research is always in progress.

Learn more biomedcentral.com/submissions 